\title{
The effects of corneal parameters on the assessment of endothelial cell density in the elderly eye
}

\section{A Müller, J P Craig, C N Grupcheva, C N J McGhee}

Background: The possible impact of corneal thickness, curvature, and size on the measurement of endothelial cell density (ECD) has largely been ignored in the normal eye. The aim of this study was to investigate the possible impact of the main corneal parameters on the analysis of ECD values at the central, superior, and temporal parts of the corneal surface.

Methods: All 75 participants (52 females, 23 males) were assessed as part of a pre-cataract surgery investigation. The mean age was 75.7 (SD 10.9) years. Confocal microscopy was used to measure ECD and the percentage of six sided cells at the central, superior, and temporal parts of the cornea. The Orbscan II topography system was used to measure corneal thickness, topography, and horizontal corneal diameter.

Results: The mean central ECD measured was 2488 (SD 301 ) cells $/ \mathrm{mm}^{2}$, compared with 2525 (SD 505) cells $/ \mathrm{mm}^{2}$ in the temporal cornea and 2639 (SD 398) cells $/ \mathrm{mm}^{2}$ in the superior cornea. The regional differences in ECD were not significant $(p>0.14)$. The central ECD was significantly correlated to the central (mean 0.593 (SD 0.039) mm, $\mathrm{p}=0.021)$ as well as the temporal $(0.628$ (SD 0.039$) \mathrm{mm}$, $p<0.001$ ) and the superior corneal thickness (SD 0.644 (SD $0.048) \mathrm{mm}, p=0.018)$. The mean corneal curvature at the centre (7.7 (SD 0.34) mm, $\mathrm{p}=0.002$ ) as well as 3 and $5 \mathrm{~mm}$ from the apex was significantly related to ECD $(p=0.008$ and $p=0.009$, respectively).

Conclusions: The study suggests that in an older population, lower ECD values would be expected in thinner and/or steeper corneas.

$\mathrm{D}$ uring the early years of life, endothelial cell density (ECD) undergoes a more rapid decline compared with that in later life. ${ }^{12}$ Although the main cause of the rapid decline in ECD has been accounted for by enlargement of the posterior corneal surface, ${ }^{3-7}$ the possible impact of corneal size, shape, and thickness on changes in ECD throughout life has largely been ignored. While a large horizontal corneal diameter was shown to correlate with a lower ECD count during early teenage years, ${ }^{8}$ ECD in young adults was reported to be lower in longer and flatter myopic eyes. ${ }^{9}$ The corneal parameter that has most commonly been assessed for its effect on ECD is corneal thickness. Although the true role of corneal thickness in the assessment of ECD in the normal eye is ambiguous, the correlation between endothelial cell dysfunction and increased corneal thickness is well established. Causes for increased corneal thickness include various diseases of the anterior segment of the eye, ${ }^{10}{ }^{11}$ contact lens wear, ${ }^{12}$ and intraocular surgery. ${ }^{13-18}$ There is also a sustained interest in the potential of corneal thickness to act as a indicator for numerous systemic and ocular diseases, including diabetic retinopathy, glaucoma, and uveitis. Besides predicting corneal disease or low endothelial cell counts, corneal thickness per se is also used to evaluate endothelial function in the normal cornea. However, few studies have investigated a possible correlation between corneal thickness and endothelial cell density in the normal eye.

Although corneal thickness is generally independent of the other morphometric parameters of the normal human eye and does not change significantly during life, ${ }^{19}{ }^{20}$ there are substantial differences in individual corneal thickness values. Whether such differences somehow affect the measurement of cell areas and therefore the analysis of ECD, remains unknown. Contradictory outcomes of studies that have reported the possible correlation between corneal thickness and ECD in the past $\mathrm{t}^{1021-23}$ could be multifactorial. The primary limitation of previous investigations is that conclusions have been drawn based on the assessment of the central corneal thickness and analysis of the central ECD only. However, numerous reports have shown there to be considerable regional differences in ECD distribution across the corneal surface. ${ }^{72-28}$ On the other hand, corneal thickness increases towards the periphery by approximately $21 \%{ }^{29}$ Correlation of these two parameters-corneal thickness and endothelial cell density - may be beneficial for morphological studies of the normal human cornea. Large interstudy variations may also partly be explained by substantial differences in the methodology and technology used for ECD estimation.

In the present study, corneal thickness, as measured by slit scanning topography and ECD values were assessed at the corneal centre as well as in the temporal and superior corneal periphery. Using in vivo confocal microscopy for the evaluation and analysis of ECD, the peripheral endothelial layer could be assessed. Although the specular microscope, as mainly used in reported studies, is useful for imaging the central corneal endothelium, it is limited in its ability to evaluate the far periphery of the cornea. ${ }^{24}$ Most studies, comparing central and peripheral ECD, describe areas that were more than $1 \mathrm{~mm}$ from the limbus. ${ }^{27}$ In the present study, however, the confocal microscope allowed imaging of the far peripheral endothelium.

The main aim of this study was to investigate the possible impact of corneal thickness, anterior and posterior corneal shape, corneal diameter, axial length, and refractive error of the eye on the analysis of ECD values across the corneal surface.

\section{METHODS}

\section{Subjects}

Seventy five participants (52 females, 23 males) were assessed as part of a pre-cataract surgery investigation. The

Abbreviations: $C C T$, central corneal thickness; ECD, endothelial cell density 
mean age was 75.7 (SD 10.9) years, ranging between 48 and 91 years. Of all participants, the majority described themselves to be of European origin (50), followed by Maori (10), Pacific Islanders (6), Asians (4), and others (6). Consent was given by all participants and ethical approval for this study was obtained from the local Auckland Ethics Committee.

\section{MEASUREMENTS \\ ECD assessment}

Prior to confocal microscopy, one drop of topical anaesthetic (Ophthetic proxymetacaine hydrochloride $5 \mathrm{mg} / \mathrm{ml}$, Allergan Australia Pty Ltd, Gordon, NSW, Australia) was instilled in the eye to be examined. One pea sized drop of immersion gel (Viscotears, Allergan Australia Pty Ltd) was applied to the tip of the objective lens of the confocal microscope (ConfoScan 2.0, NIDEK Technologies, Greensboro, NC, USA). The microscope was brought into position using a joystick and the lens was aligned with the eye. With the drop of gel in contact with the surface of the eye, scan images of the central cornea were captured. The patient was then asked to fixate on set targets placed $2.5 \mathrm{~mm}$ off the central gaze and approximately $7 \mathrm{~cm}$ from the eye, so that the temporal and superior parts of the cornea (approximately $1 \mathrm{~mm}$ from the limbus) could be scanned.

Approximately 300 images were obtained per scan. Based on the best visibility of endothelial cells, three representative frames from each scan were chosen for analysis. The maximum examination time was 10 minutes in total. All captured images were analysed using the NAVIS (NIDEK Technologies). The chosen frame size, or region of interest (ROI), was $0.035 \mathrm{~mm}^{2}$. Using manual assisted cell counts, as many clearly visible cells as possible were analysed within each frame. The mean values for endothelial cell density, cell area, and the percentage of six sided cells within each of the three frames were recorded and averages for each cornea were calculated.

\section{Corneal parameters}

The Orbscan II slit scanning corneal topography system (Orbscan, Bausch and Lomb, Salt Lake City, UT, USA) was used to measure corneal thickness and horizontal corneal diameter, and assess corneal topography. Before measurement, the subject's head was aligned with the instrument and a head strap was placed around the back of the head. The subject was advised to keep both eyes open and fixate on the target. By viewing the live image of the eye on the monitor, the examiner aligned the two fixation markers reflected by the instrument on the corneal surface before performing the scan. Three scans were performed per cornea and the mean values for the central, temporal, and superior corneal thickness, the horizontal diameter, the spherical equivalent (least square method of determining best fit sphere), and eccentricity of the anterior and posterior surface were recorded. The instrument is designed in a way that peripheral corneal thickness is measured $3 \mathrm{~mm}$ from the corneal centre, within a circle of $2 \mathrm{~mm}$. Axial length was measured with an A-scan ultrasound (Tomey AL-2000, Tomey, Erlangen, Germany) and an autorefractor (Topcon KR-8100 Topcon America, Paramus, NJ, USA) was used for refractive error assessment. For each eye, a minimum of 10 axial length recordings were made and the mean calculated. Three measures were taken for each of the later two investigations and the mean value used for statistical analysis.

\section{Visual acuity}

Visual acuity was measured using a single new, calibrated, $4 \mathrm{~m}$ illuminated LogMAR chart (University of Otago, NZ).

\section{Statistical analysis}

The Kolmogorov-Smirnov test was used to assess normality and the level of significance was set at $\mathrm{p}<0.05$. According to whether or not the distributions of data sets were normal, the means of variables between different groups were compared by Student's $t$ tests or a Mann-Whitney U test, respectively. Again, the level of significance was set at $p<0.05$. The Pearson coefficient of correlation was used to test correlation between parameters. If the Pearson correlation analysis revealed any parameters to be correlated, the significance of these variables was further tested by multiple regression analysis. The value of significance of the slopes was defined ( $p$ value) as well as the value for the correlation coefficient ( $r$ value). Mean (standard deviation, SD) values are described.

\section{RESULTS}

\section{Central endothelial cell density}

The ECD characteristics for the central, temporal and superior cornea are shown in table 1 . The analysis of each cornea included between 77 and 131 clearly visible cells. There was no significant sex related difference in central ECD (mean ECD in females 2494 (SD 300) cells $/ \mathrm{mm}^{2}$, mean ECD in males 2472 (SD 303) cells $/ \mathrm{mm}^{2}, \mathrm{p}=0.76$ ) and the values were normally distributed $(\mathrm{p}>0.15)$.

\section{Peripheral endothelial cell density}

Both mean and median ECD, assessed for the temporal and superior part of the cornea, are shown in table 1 . The mean temporal ECD value was slightly higher then the central ECD value (by $2 \%$ ). Compared with the average central ECD value, superior ECD was $4 \%$ higher. Temporal and superior ECD values were slightly skewed $(p=0.01$ and $p=0.041$, respectively) and the differences in mean ECD between central, temporal, and superior cornea were not significant $(\mathrm{p}>0.05)$. There were also few, if any, differences with respect to sex in all three areas assessed and none could be shown to be significant $(\mathrm{p}>0.7)$.

\section{Percentage of six sided cells}

Differences in the type of endothelial cells are commonly investigated by assessing the proportion of cells that are six sided ("percentage of hexagonality"). Values of six sided cells, measured centrally for the 75 corneas examined, are shown in table 1 . Values were normally distributed $(p>0.05)$ with a small sex difference (males 48.1 (SD 6.5) \%, females 46.5 (SD 5.9) \%), which was not significant $(p=0.31)$. Comparison of the percentage of six sided cells in the central cornea between subjects of European origin and of Maori origin revealed identical mean values (European 47.0 (SD 6.6) \%, Maori 47.0 (SD 5.2) \%). The mean numbers of six sided cells at the temporal area (47.2 (SD 4.6) \%, median $47.0 \%$, range $37.0-56.0 \%)$, as well as the superior area $(46.7$ (SD 6.9) \%, median $49.0 \%$, range $36.0-59.0 \%$ ) of the set of endothelia were not significantly different from the central part $(p>0.32)$. There were no significant differences in values with respect to sex $(\mathrm{p}>0.05)$.

\section{Corneal thickness}

Measured central corneal thickness (CCT) values are shown in table 1. There was no sex related difference in CCT $(p=0.97)$. Values for each site were normally distributed $(\mathrm{p}>0.15)$. The mean thickness of the temporal cornea was $23.6 \%$ higher than the central corneal thickness (0.628 (SD 0.039 ) $\mathrm{mm}$, range $0.553-0.729 \mathrm{~mm}$, median $0.627 \mathrm{~mm}$ ) but slightly lower than the superior cornea $(0.644$ (SD 0.048 ) $\mathrm{mm}$, range 0.434 to $0.754 \mathrm{~mm}$, median $0.635 \mathrm{~mm}$ ). Superior thickness was $26.7 \%$ higher than CCT, table 1 . All regional differences in corneal thickness were significant 
Table 1 Measured mean values for corneal thickness, ECD, cell area, and percentage of six sided cells at the central, temporal, and superior cornea

\begin{tabular}{|c|c|c|c|c|c|c|c|c|c|}
\hline & \multicolumn{3}{|l|}{ Central cornea } & \multicolumn{3}{|c|}{ Temporal cornea } & \multicolumn{3}{|l|}{ Superior cornea } \\
\hline & Mean (SD) & Median & Range & Mean (SD) & Median & Range & Mean (SD) & Median & Range \\
\hline $\mathrm{CT}(\mathrm{mm})$ & $0.593(0.039)$ & 0.594 & $0.508-0.693$ & $0.628(0.039)$ & 0.627 & $0.553-0.729$ & $0.644(0.048)$ & 0.635 & $0.434-0.754$ \\
\hline $\mathrm{ECD}$ (cells $/ \mathrm{mm}^{2}$ ) & $2488(299)$ & 2446 & $1865-3386$ & $2525(505)$ & 2404 & $1872-3550$ & 2639 (398) & 2595 & $1839-3510$ \\
\hline Cell area $\left(\mu \mathrm{m}^{2}\right)$ & 409 (49) & 410 & $296-536$ & $411(73)$ & 417 & $283-538$ & $388(58)$ & 386 & $285-545$ \\
\hline Six sided cells (\%) & $47.0(6.1)$ & 47.0 & $32.0-60.0$ & $47.2(4.6)$ & 47.0 & $37.0-56.0$ & $46.7(7.0)$ & 49.0 & $36.0-59.0$ \\
\hline
\end{tabular}

$(\mathrm{p}<0.04)$. The small sex related difference in the temporal and superior cornea was not significant $(\mathrm{p}>0.4)$.

When the mean central ECD values were statistically compared with central corneal thickness values, a positive and statistically significant correlation was evident (Pearson's $r=0.27, \mathrm{p}=0.021$, multiple regression $\mathrm{p}=0.01$ ), suggesting that lower ECD values were measured in thinner corneas (ECD increased by 212 cells $/ \mathrm{mm}^{2}$ per $0.1 \mathrm{~mm}$ increase in corneal thickness, fig 1). The same positive trend was evident when central ECD was compared with temporal corneal thickness $(r=0.44, \mathrm{p}<0.001$; ECD increased by 333 cells $/ \mathrm{mm}^{2}$ per $0.1 \mathrm{~mm}$ increase in corneal thickness, fig 2) and superior corneal thickness $(r=0.34, \mathrm{p}=0.003$; ECD increased by 224 cells $/ \mathrm{mm}^{2}$ per $0.1 \mathrm{~mm}$ increase in corneal thickness, fig 3).

Mean superior ECD values were also significantly correlated, in a similar fashion to central ECD, with corneal thickness values at the superior $(r=0.48, \mathrm{p}=0.018)$, central $(r=0.41, \mathrm{p}=0.049)$, and temporal $(r=0.45, \mathrm{p}=0.028)$ cornea. Temporal ECD values were largely independent of corneal thickness at the temporal $(r=0.37, \mathrm{p}=0.122)$, central $(r=0.34, \mathrm{p}=0.16)$, and superior site $(r=0.26$, $\mathrm{p}=0.289)$.

\section{Corneal curvature}

The mean anterior eccentricity (as measured with the Orbscan II instrument) for all corneas assessed was 0.317 (SD 0.363) (median 0.370), indicating that the mean anterior cornea assessed followed the shape of a prolate ellipse (flattening peripherally). The mean overall anterior corneal curvature was 7.77 (SD 0.34 ) mm (median $7.78 \mathrm{~mm}$ ), ranging from 7.14 to $8.83 \mathrm{~mm}$ and values were skewed $(\mathrm{p}<0.01)$. Statistical analysis showed the overall anterior corneal curvature (equivalent of spherical radius of curvature) to be significantly related to mean central ECD (Pearson's $r=0.36, \quad \mathrm{p}=0.002 ;$ multiple regression $\mathrm{p}=0.002$ ), (fig 4).

The same positive correlation was found when central ECD was compared with the anterior curvature at $3 \mathrm{~mm}$

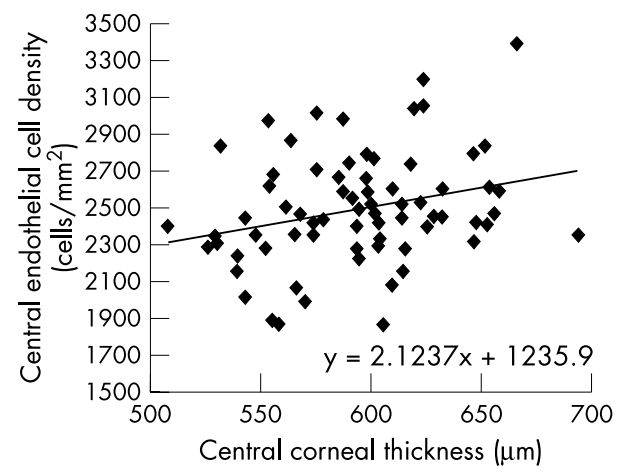

Figure 1 Relation between measured central corneal thickness and central endothelial cell density before cataract surgery. $(r=-0.311, \mathrm{p}=0.009)$ and at $5 \mathrm{~mm}$ from the corneal apex $(r=-0.317, \mathrm{p}=0.008)$. Results suggest that lower ECD values would be expected in steeper corneas.

The mean posterior corneal curvature (equivalent of spherical radius of curvature) was 6.68 (SD 0.36) mm (range 5.9 to $7.57 \mathrm{~mm}$, median $6.64 \mathrm{~mm}$ ). The distribution of values appeared normal $(p=0.15)$. Again, the mean eccentricity of 0.350 (median 0.385 ) indicated peripheral flattening of the posterior surface. Although there was a clear trend for the average posterior curvature to be positively correlated to central ECD, this trend was not significant $(r=0.21$, $\mathrm{p}=0.08$ ). The small differences with respect to sex in average anterior and posterior curvature were not significant $(\mathrm{p}=0.41$ and $\mathrm{p}=0.09$, respectively $)$.

\section{Axial length of the eye}

The mean axial length of the eyes studied was 23.16 (SD 0.93 ) mm (median 22.99, range 21.71-27.12 $\mathrm{mm}$ ) and values were normally distributed $(\mathrm{p}=0.15)$. There was a small, but not statistically significant, difference between male subjects

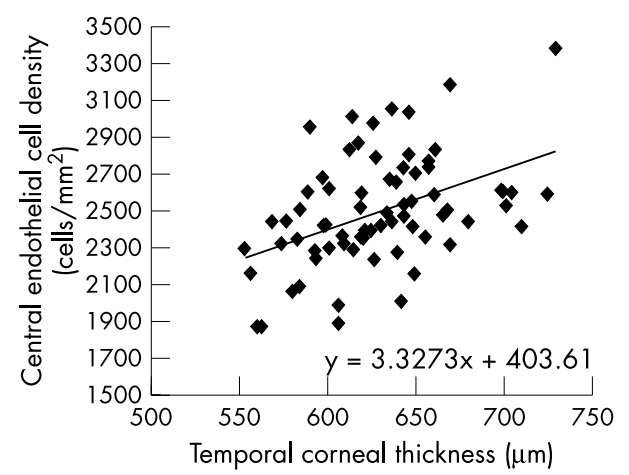

Figure 2 Relation between measured temporal corneal thickness and central endothelial cell density before cataract surgery.

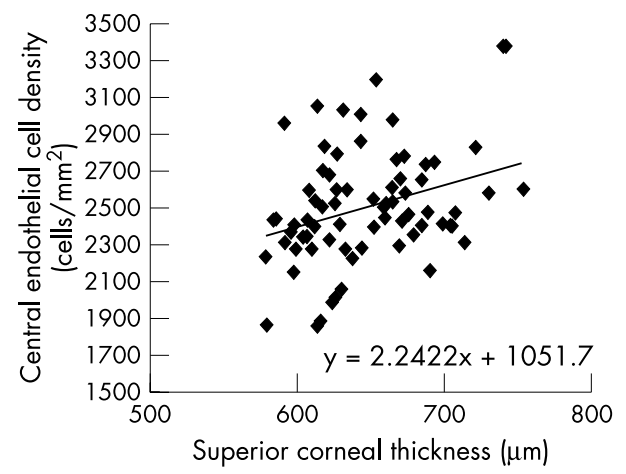

Figure 3 Relation between measured superior corneal thickness and central endothelial cell density before cataract surgery. 


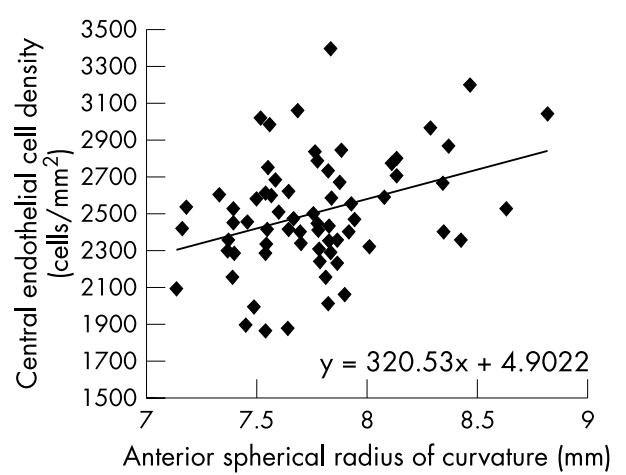

Figure 4 Relation between the measured anterior spherical corneal radius and central endothelial cell density before cataract surgery.

(mean 23.33 (SD 1.21) mm) and female subjects (23.15 $(0.88) \mathrm{mm})$. When axial length values were compared with central ECD values, a negative trend was evident (fig 5). The trend suggested that eyes with longer axial length values are associated with a lower central ECD. This trend was statistically significant (Pearson's $r=-0.235, \mathrm{p}=0.04$, multiple regression $\mathrm{p}=0.038$ ).

\section{Horizontal corneal diameter}

Comparison revealed central as well as peripheral ECD values to be independent of mean horizontal corneal diameter values (mean 11.78 (SD 0.66 ) mm, median $11.7 \mathrm{~mm}$, range $10-13.6 \mathrm{~mm})$, indicating that corneal diameter, at least within the age range studied, is not an indicator of cell density. Mean values were normally distributed $(\mathrm{p}>0.15)$ and were slightly higher in males (11.9 (0.4) mm) compared with females (11.7 (0.7) $\mathrm{mm})$; however, this difference was not significant $(\mathrm{p}=0.15)$.

\section{Refractive error}

The mean spherical equivalent of the refractive error for all subjects included was -0.68 (SD 2.78) D (median $0.0 \mathrm{D}$, range -9.13 to $+4.0 \mathrm{D}$ ). Comparison with axial length values confirmed a trend in which more myopic eyes were longer $(r=-0.323, \mathrm{p}=0.005)$. Refractive error did not correlate with ECD $(r=0.078, \mathrm{p}=0.74)$.

\section{Visual acuity}

The mean VA (LogMAR) was 0.62 (SD 0.27). The median VA was 0.6 and values reached between $0.2-1.3$.

\section{DISCUSSION}

Although the swelling response of the cornea to any alterations in endothelial barrier and pump functions is well established, there is a lack of information about the possible role of differences in corneal thickness or shape in the assessment of ECD values in the normal eye. Whereas the current study suggests that central ECD values are correlated to the thickness of the central, temporal, and superior cornea within an elderly population, existing studies show substantial variation in outcome. Most studies have reported no correlation between CCT and ECD in the older eye, ${ }^{1021} 23$ supporting the theory that corneal thickness is merely an independent parameter of the normal cornea.

Others have suggested the existence of such a correlation in children. ${ }^{8}$ In table 2, details on reports assessing the corneal thickness and ECD are summarised. The contradictory reports may be explained by lack of consideration of possible regional differences in ECD distributions and substantial differences in corneal thickness or corneal curvature values across the cornea. In order to understand

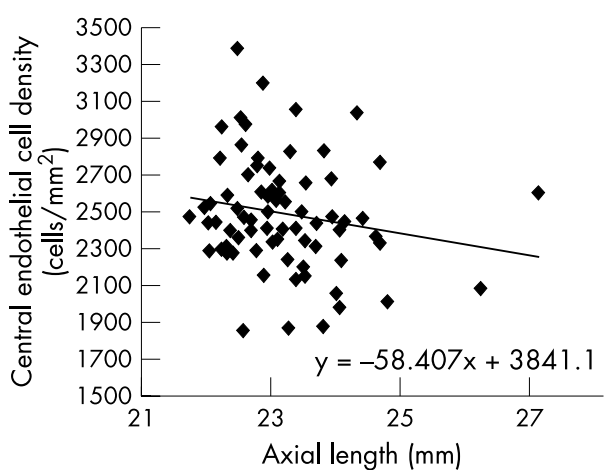

Figure 5 Relation between measured axial length and central endothelial cell density before cataract surgery.

the potential effect of any changes in corneal parameters on the endothelial cell layer, or its appearance, exact knowledge of the overall cell distribution is needed.

Measurement of the peripheral ECD in vivo is still uncommon and reported values show large variation. ${ }^{25-27}$ Studies have applied either direct microscopic examination of the endothelia of cadaver eyes ${ }^{24} 3132$ or, most commonly, used specular microscopy for ECD assessment. ${ }^{26} 2833$ Central ECD values in eyes with cataracts, within similar age ranges as the current study, have previously been reported in various studies and the mean values ranged between 2324 and 3093 cells $/ \mathrm{mm}^{2}{ }^{34-39}$ The mean value for ECD measured in the current study ( 2488 cells $/ \mathrm{mm}^{2}$ ) appears to be in agreement with the previously reported values. While ECD values in the literature have most commonly been assessed at the corneal centre only, the present study indicates central ECD values to be $2 \%$ lower than the temporal and $4 \%$ lower than the superior cornea. There are a number of reports in the literature supporting such a trend of higher cell densities in the peripheral cornea. Sturrock et al, using a specular microscope, reported central ECD values to be $2.8 \%$ below nasal ECD and 3.6\% below temporal ECD values. ${ }^{26}$ Assessing ECD in cadaver eyes, Daus et al reported the maximal peripheral density to be on average 1374 cells $/ \mathrm{mm}^{2}$ higher then at the corneal centre. ${ }^{25}$ Schimmelpfennig, found ECD values at the far corneal periphery of cadaver eyes to be as much as 30\% higher. ${ }^{24}$ Some studies have not found any significant regional differences in ECD across the cornea ${ }^{33} 40$; however, others have reported peripheral ECD values to be lower compared with central ECD values ${ }^{27}$ or have suggested that there is a vertical gradient in cell density. ${ }^{28}$

Besides any true regional differences in ECD distribution, there could be some optical, and therefore artefactual, explanation for a correlation between corneal thickness and ECD. The impact of increased peripheral corneal thickness on the magnification of the microscope photographing the endothelial layer was described almost 30 years ago. ${ }^{41}$ In the present study, higher ECD values were measured in the flatter periphery of the elliptical cornea. The increased peripheral corneal thickness is compensated by a steeper posterior corneal curvature. When the endothelium is scanned by the confocal microscope, images are taken from a static position, ignoring posterior corneal curvature changes. It could therefore be argued that the appearance of the highly magnified endothelial cells in the corneal periphery is distorted by the steeper angle under which it is photographed. Such a distortion could cause the area of the cells to appear reduced and therefore artificially increase cell density measures in the peripheral cornea.

The present study suggests that lower ECD values would possibly be expected in longer eyes. The same trend has 
Table 2 Previous studies reporting corneal thickness and ECD in the human eye

\begin{tabular}{|c|c|c|c|c|c|}
\hline & $\mathrm{N}$ & $\begin{array}{l}\text { Mean (SD) age } \\
\text { (years) }\end{array}$ & $\begin{array}{l}\text { Mean (SD) corneal thickness } \\
(\mathrm{mm})\end{array}$ & $\begin{array}{l}\text { Mean (SD) ECD } \\
\left(\text { cells } / \mu \mathrm{m}^{2}\right)\end{array}$ & $\begin{array}{l}\text { Significant } \\
\text { correlation }\end{array}$ \\
\hline Sawa et al, 1982 & $46^{*}$ & $15-87$ & 0.524 (central)§ & $1053(3067)^{* *}$ & No \\
\hline $\begin{array}{l}\text { Kohlhaas et al, } \\
1997\end{array}$ & $48+$ & $70.7(4.5)$ & $\begin{array}{l}0.520(0.052) \text { (central)§ } \\
0.650(0.062)(12 \mathrm{~h}) \S\end{array}$ & $\begin{array}{l}2551 \text { (345) } \\
\text { (central)+† } 2550 \\
\text { (366) }(12 \mathrm{~h})+\dagger\end{array}$ & No \\
\hline Müller, 2000 & $108 \mp$ & $10.1(3.1)$ & $0.528(0.033)$ (central)§ & $\begin{array}{l}3542(510) \\
\text { (central)** }^{* *}\end{array}$ & $\begin{array}{l}\text { Yes, }(p=0.019, \\
r=0.32)\end{array}$ \\
\hline $\begin{array}{l}\text { Ventura et al, } \\
2001\end{array}$ & $30+$ & 71 (15) & 0.537 (0.027) (central) & $\begin{array}{l}\text { Approx } 2400 \\
\text { (central)** }\end{array}$ & No \\
\hline \multicolumn{6}{|c|}{$\begin{array}{l}\text { *Corneal graft. } \\
\text { †Pre-cataract. } \\
\text { †Normal cornea. } \\
\text { §Ultrasound pachymetry. } \\
\text { † Optical low coherence relflectometer and ultrasound pachymetry. } \\
\text { **Non-contact specular microscopy. } \\
\text { †Contact specular microscopy. }\end{array}$} \\
\hline
\end{tabular}

recently been reported by Chang et al. ${ }^{9}$ In their study, the authors have suggested the elongation of the axial length leads to an increase in endothelial surface area. Because of a lack of mitotic activity of the corneal endothelium after birth, spreading of the endothelial cells is expected in order to cover the enlarged surface. This, in return, reduces ECD. ${ }^{9}$ However, the true optical effects caused by differences in thickness and shape of the anterior and posterior corneal surfaces are as yet insufficiently assessed. Detailed modelling studies are needed, determining the degree to which corneal parameters potentially affect the measurement of endothelial cell area, as it appears through the specular or confocal microscope.

Although ECD is most commonly used to describe the state of health of the corneal endothelium, a high percentage of six sided cells is also seen as an indicator of a healthy corneal endothelium. The mean percentage of six sided cells measured in the present study was 47.0 (SD 6.1), which is less than most mean values previously reported in the literature. Assessing eyes with cataracts within similar, older age groups, studies have reported mean values for six sided cells between $51 \%$ and $73 \% .{ }^{34-38}$ However, in a recent study by Snellingen et $a l^{39}$ the mean percentage of six sided cells measured in 1235 eyes with cataracts, using a semiautomatic analysis technique, was even lower than in the present study $(40 \%)$. The comparison of cell shapes in the central, temporal, and superior part of the cornea revealed no significant differences. The minor regional differences in values indicate that the different types of cells (based of the number of cell sides) are evenly distributed across the inner surface of the cornea. Whereas Snellingen et al have reported significant differences between ethnic groups in endothelial cell density and hexagonality, no such differences were found in the present study, comparing subjects of white and Maori origin. However, it must be noted that the sample size is small. The percentage of six sided cells appears independent of any corneal parameters assessed.

In conclusion, the current study suggests that, at least within the age range studied, lower endothelial cell density values would be expected in thinner and/or steeper corneas. The question of whether these are genuinely related or caused by optical artifacts remains unanswered. Based on a meta-analysis by Doughty and Zaman, ${ }^{29}$ normal CCT in white adults would be expected to be within SD $11.6 \%$ of $0.535 \mathrm{~mm}$, that is, $0.473-0.597 \mathrm{~mm}$. Although the mean CCT value in the present study is just within these limits $(0.593 \mathrm{~mm})$, it could be argued that this is towards the higher end of what would be expected for the age group assessed. The Orbscan instrument allows measures of corneal thickness and curvature at any point on the corneal surface and its accuracy, precision, ${ }^{42}{ }^{43}$ and repeatability ${ }^{44}$ have been reported to be acceptable for its use in research. However, it is recognised that the Orbscan overestimates corneal thickness compared with the more commonly used technique of ultrasound pachymetry. ${ }^{44-46}$ The reported difference between the two methods varies from $20 \mu \mathrm{m}^{45}$ to $28 \mu \mathrm{m}^{46}$ or approximately $5 \%$. One possible explanation is that the Orbscan, due to its non-contact type of measurement, may include the hydrated mucous gel covering the corneal surface in its measurement. ${ }^{45} 47$

Future studies should focus on the investigation of the effects of corneal parameters on assessment of ECD within specific age groups. Although the horizontal corneal diameter is a clear indicator for ECD during infancy ${ }^{2}{ }^{3}$ and childhood up to early teenage years, ${ }^{8}$ the present study suggests that it is not correlated with ECD assessment in the elderly. However, unlike in the young cornea, ${ }^{8}$ corneal thickness plays a significant role when ECD is measured in the older eye. Although corneal thickness is generally seen as an independent dimension that does not change significantly after infancy, ${ }^{48}$ a small decrease in value throughout life has been previously suggested. ${ }^{49}$ The effects of such changes in corneal thickness on the assessment of declining ECD during life should be investigated within different age groups and populations in order to better understand differences in ECD and the implications of such differences between individuals.

\section{ACKNOWLEDGEMENTS}

The authors would like to thank Dr Andrew Riley for his contribution to the research, particularly for the collection of data and clinical assessment of patients.

\section{Authors' affiliations \\ A Müller, J P Craig, C N Grupcheva, C N J McGhee, Department of Ophthalmology, The University of Auckland, Auckland, New Zealand}

Correspondence to: Dr Andreas Müller, The University of Auckland, Private Bag 92019, Auckland, New Zealand; a.muller@auckland.ac.nz

Accepted for publication 13 June 2003

\section{REFERENCES}

1 Laule A, Cable MK, Hoffman CE, et al. Endothelial cell population changes of human cornea during life. Arch Ophthalmol 1978;96:2031-5.

2 Murphy C, Alvarado J, Juster R, et al. Prenatal and postnatal cellularity of the human corneal endothelium. Invest Ophthalmol Vis Sci 1984;25:312-22.

3 Hiles D, Biglan A, Fetherolf E. Central corneal endothelial cell count in children. Am Intr-Ocular Implant Soc J 1979;5:292-300.

4 Hiles D. Discussion to 'normal endothelial cell count range'. Ophthalmology 1980;87:865-6.

5 Speedwell L, Novakovic P, Sherrard ES, et al. The infant corneal endothelium Arch Ophthalmol 1988;106:771-5. 
6 Tsukahara $Y$, Yamamoto M. Postnatal development of corneal endothelial cells in normal children. Acta Soc Ophthalmol Jpn 1989;93:763-8.

7 Nucci $P$, Brancato $R$, Mets $M$, et al. Normal endothelial cell density range in childhood. Arch Ophthalmol 1990;108:247-8.

8 Müller A. Assessment of eye growth-related changes in the corneal endothelium of children and young teenagers. Glasgow Caledonian University PhD Thesis, 2000

9 Chang SW, Tsai IL, Hu FR, et al. The cornea in young myopic adults. Br J Ophthalmol 2001:85:916-20.

10 Ventura AC, Walti R, Bohnke M. Corneal thickness and endothelial density before and after cataract surgery. Br J Ophthalmol 2001;85:18-20.

11 Burns RR, Bourne WM, Brubaker RF. Endothelial function in patients with cornea guttata. Invest Ophthalmol Vis Sci 1981;20:77-85.

12 Erickson P, Doughty MJ, Comstock TL, et al. Endothelial cell density and contact lens-induced corneal swelling. Cornea 1998;17:152-7.

13 Amon M, Menapace R, Radax U, et al. Endothelial density and corneal pachometry after no-stitch, small-incision cataract surgery. Documenta Ophthalmologica 1992:81:301-7.

14 Olsen T. Corneal thickness and endothelial damage after intracapsular cataract extraction. Acta Ophthalmol 1980;58:424-33.

15 Cheng H, Sturrock GD, Rubinstein B, et al. Endothelial cell loss and cornea thickness after intracapsular extraction and iris clip lens implantation: a randomised controlled trial (interim report). Br J Ophthalmol 1977;61:785-90.

16 Cheng H, Bates AK, Wood L, et al. Positive correlation of corneal thickness. Arch Ophthalmol 1988;106:920-2.

17 Ravalico G, Tognetto D, Palomba MA, et al. Corneal endothelial function after extracapsular cataract extraction and phacoemulsification. J Cataract Refract Surg 1997;23:1000-5.

18 Matsuda M, Suda T, Manabe R. Serial alterations in endothelial cell shape and pattern after intraocular surgery. Am J Ophthalmol 1984;98:313-19.

19 Korey M, Gieser D, Kass MA, et al. Central corneal endothelial cell density and central corneal thickness in ocular hypertension and primary open-angle glaucoma. Am J Ophthalmol 1982;94:610-16.

20 Puska P, Vasara K, Harju M, et al. Corneal thickness and corneal endothelium in normotensive subjects with unilateral exfoliation syndrome. Graefes Arch Clin Exp Ophthalmol 2000;238:659-63.

21 Sawa M, Araie M, Tanishima T. Permeability of the corneal endothelium to fluoresein-a follow up of keratoplasty cases. Jpn J Ophthalmol 1982;26:326-37

22 Kaufman HE, Capella JA, Robbins JE. The human corneal endothelium. Am J Ophthalmol 1966:61:835-41.

23 Kohlhaas M, Stahlhut O, Tholuck J, et al. Entwicklung der Hornhautdicke und -endothelzelldichte nach Kataraktextraktion mittels Phakoemulsifikation. Ophthalmologe 1997:94:515-18.

24 Schimmelpfennig BH. Direct and indirect determination of non-uniform cell density distribution in human corneal endothelium. Invest Ophthalmol Vis Sci 1984;25:223-9.

25 Daus W, Voelcker HE, Maysen H. Clinical significance of age-related regional differences in distribution of human corneal endothelium. Klin Monatsbl Augenheilk 1990;196:449-55.

26 Sturrock GD, Sherrard ES, Rice NSC. Specular microscopy of the corneal endothelium. Br J Ophthalmol 1978;62:809-14

27 Wiffen SJ, Hodge DO, Bourne WM. The effect of contact lens wear on the central and peripheral corneal endothelium. Cornea 2000;19:47-51.

28 Azen SP, Smith RE, Burg KA, et al. Variation in central and vertical corneal endothelial cell density in normal subjects. Acta Ophthalmol 1981;59:94-9.
29 Doughty MJ, Zaman ML. Human corneal thickness and its impact on intraocular pressure measures: a review and meta-analysis approach. Surv Ophthalmol 2000;44:367-408.

30 Khodadoust AA, Green K. Physiological function of regenerating endothelium. Invest Ophthalmol Vis Sci 1976;15:96-101.

31 Sperling S. Indirect evaluation of corneal endothelial cell density. Acta Ophthalmol 1978;56:445-54.

32 Binder PS, Akers P, Zavala EY. Endothelial cell density determined by specular microscopy and scanning electron microscopy. Ophthalmology 1979;86:1831-47

33 Yee RW, Matsuda M, Schultz RO, et al. Changes in the normal corneal endothelial cellular pattern as a function of age. Curr Eye Res 1985;4:671-8.

34 Ohguro N, Matsuda M, Kinoshita S. Effects of posterior chamber lens implantation on the endothelium of transplanted corneas. Br J Ophthalmol 1997;81:1056-9.

35 Padmanabhan P, Basti S, Murugesan R. Effect of two anterior capsulotomy techniques on the corneal endothelium. J Cataract Refract Surg 1994;20:504-6.

36 Matheu A, Castilla M, Duch F, et al. Manual nucleofragmentation and endothelial cell loss. J Cataract Refract Surg 1997;22:995-9.

37 Johnston RH, Hasany S, Rootman DS. Endothelial cell analysis of corneas from donor eyes with an intraocular lens: a comparative study. Cornea 1997; 16:531-3.

38 Glasser DB, Matsuda M, Gager WE, et al. Corneal endothelial morphology after anterior chamber lens implantation. Arch Ophthalmol 1985; 103:1347-9.

39 Snellingen T, Rao GN, Shrestha JK, et al. Quantitative and morphological characteristics of the human corneal endothelium in relation to age, gender, and ethnicity in cataract populations of South Asia. Cornea 2001;20:55-8.

40 Blackwell WL, Gravenstein H, Kaufman HE. Comparison of central corneal endothelial cell numbers with peripheral areas. Am J Ophthalmol 1977:84:473-6.

41 Bourne WM, Enoch JM. Some optical principles of the optical specular microscope. Invest Ophthalmol 1976;15:29-31.

42 Lattimore MR, Kaupp S, Schallhorn S, et al. Orbscan Pachymetry: implications of a repeated measures and diurnal variation analysis. Ophthalmology 1999;106:977-81.

43 Yaylali V, Kaufman SC, Thompson HW. Corneal thickness measurements with the Orbscan Topography System and ultrasonic pachymetry. J Cataract Refract Surg 1997;23:1345-50.

44 Marsich MM, Bullimore MA. The repeatability of corneal thickness measures. Cornea 2000;19:792-5.

45 Liu Z, Huang AJ, Pflugfelder SC. Evaluation of corneal thickness and topography in normal eyes using the Orbscan corneal topography system. Br J Ophthalmol 1999:83:774-8.

46 Chakrabarti HS, Craig JP, Brahma A, et al. Comparison of corneal thickness measurements using ultrasound and Orbscan slit-scanning topography in normal and post-LASIK eyes. J Cataract Refract Surg 2001;27:1-6.

47 Prydal JI, Artal P, Woon H, et al. Study of human precorneal tear film thickness and structure using laser interferometry. Invest Ophthalmol Vis Sci 1982;33:2006-11.

48 Ehlers N, Sorensen T, Bramsen T, et al. Central corneal thickness in newborns and children. Acta Ophthalmologica 1976:54:285-90.

49 Olsen T, Ehlers N. The thickness of the human cornea as determined by a specular microscope. Acta Ophthalmologica 1984;62:859-71. 